\title{
Gonadal function after combination chemotherapy for Hodgkin's disease in childhood
}

\author{
E WHITEHEAD, S M SHALET, P H MORRIS JONES, C G BEARDWELL, AND D P DEAKIN
}

\author{
Christie Hospital and Royal Manchester Children's Hospital, Manchester
}

SUMMARY The effect of quadruple chemotherapy (mustine, vincristine, procarbazine, and prednisolone) on gonadal function was investigated in 15 males and 2 females treated for Hodgkin's disease during childhood. The 2 females have regular menstrual cycles with evidence of ovulation in one. Twelve of the males have shown normal progression of pubertal development since completing their treatment. Nine out of 10 late pubertal or adult subjects had small testes but only one developed gynaecomastia. All 4 prepubertal subjects had normal basal and peak gonadotrophin responses to luteinising hormone-releasing hormone. Nine of the 12 subjects studied during puberty or adulthood had either an increased basal serum follicle-stimulating hormone (FSH) level or an exaggerated FSH response to luteinising hormone-releasing hormone. Each of the 6 males who provided semen for analysis was azoospermic after an interval of between 2.4 and 8 (mean $5 \cdot 3$ ) years after completion of treatment. We conclude that severe testicular damage is common after treatment with mustine, vincristine, procarbazine, and prednisolone in childhood. The germinal epithelium is particularly vulnerable and the resultant azoospermia is likely to be irreversible. The Leydig cells are less susceptible to cytotoxic-induced damage. Pubertal development is normal and there is no indication for androgen replacement therapy.

Combination chemotherapy has greatly improved the prognosis for patients treated for Hodgkin's disease. This has resulted in the survival of an increasing number of young patients, cured of this cancer, but at risk from the long-term side effects of chemotherapy. Almost all men treated with at least 6 courses of MVPP (mustine, vinblastine, procarbazine, and prednisolone) or MOPP (mustine, vincristine, procarbazine, and prednisolone) for Hodgkin's disease are rendered permanently azoospermic. $^{120}$ Gonadal function in women is less severely affected by MVPP chemotherapy. In patients studied by Chapman et al. ${ }^{2}$ there was a $62 \%$ incidence of amenorrhoea after completion of treatment. There has only been one study of chemotherapy-induced gonadal dysfunction in patients treated for Hodgkin's disease in childhood; in that study Sherins et al. $^{3}$ found some evidence of reversible damage to the tubular system and, more surprisingly, Leydig cell dysfunction, clinically manifested by gynaecomastia. If Leydig cell function is impaired normal pubertal maturation may be affected. We have therefore studied survivors of childhood Hodgkin's disease who received similar treatment, to find out if puberty was normal and to define further the damage to the tubular system.

\section{Patients and methods}

Fifteen males and 2 females, treated for Hodgkin's disease during childhood, were studied. All except one patient had previously received combination chemotherapy with MOPP. Table 1 shows the drug doses, ages at treatment, and the length of time between the end of treatment and gonadal function tests. Fifteen of the $\mathbf{1 7}$ had received neck or mantle irradiation with a dose between 2500 and $3000 \mathrm{cGy}$ (in 16-20 fractions over 20-27 days.) Five males (Cases 5, 11, 12, 13, and 14) had received abdominal irradiation and, despite lead shielding, the radiation dose received by the testes had been between 100 and $300 \mathrm{cGy}$ (in a fractionated course over 3-4 weeks).

All patients were in clinical remission at the time of the study. The pubertal status of each was defined by the staging technique of Tanner. ${ }^{4}$ Testicular size was assessed by comparison with the standards of the Prader orchidometer. Each male patient had a cannula inserted into an antecubital vein and blood taken for basal levels of triiodothyronine, thyroxine, thyroid-stimulating hormone (TSH), testosterone, luteinising hormone (LH), and follicle-stimulating hormone (FSH). Serum FSH and $\mathrm{LH}$ concentrations were also measured 20 and 
Table 1 Age at treatment, length of time between treatment and study, and drug doses received by each patient

\begin{tabular}{|c|c|c|c|c|c|c|c|c|}
\hline \multirow[t]{2}{*}{ Case } & \multirow[t]{2}{*}{$\operatorname{sex}$} & \multirow{2}{*}{$\begin{array}{l}\text { Age (years) at } \\
\text { start of treatment }\end{array}$} & \multicolumn{4}{|c|}{ Drug doses $\left(m g / m^{2}\right)$} & \multirow{2}{*}{$\begin{array}{l}\text { Duration } \\
\text { of treatment } \\
\text { (months) }\end{array}$} & \multirow{2}{*}{$\begin{array}{l}\text { Time between end of treatment } \\
\text { and study (years) }\end{array}$} \\
\hline & & & Mustine & Vincristine & Prednisolone & Procarbazine & & \\
\hline 1 & $\mathbf{M}$ & $13 \cdot 8$ & 72 & 18 & 3360 & 5800 & 10 & $4 \cdot 3$ \\
\hline 2 & $\mathbf{M}$ & 4.8 & 72 & 18 & 6720 & 16800 & 13 & 4 \\
\hline 3 & $\mathbf{M}$ & $12 \cdot 7$ & 84 & 21 & 2520 & 6300 & 12 & $1 \cdot 2$ \\
\hline 4 & $\mathbf{M}$ & 14 & 132 & 36 & 6720 & 16800 & 20 & (a) 0.7 (b) 1.4 \\
\hline 5 & $\mathbf{M}$ & $8 \cdot 3$ & $18^{*}$ & 27 & 2205 & 12450 & 24 & (a) 2.3 (b) 4.4 \\
\hline 6 & $\mathbf{M}$ & $12 \cdot 1$ & 84 & 27 & 3360 & 16800 & 32 & $3 \cdot 1$ \\
\hline 7 & $\mathbf{M}$ & $11 \cdot 2$ & 66 & 17 & 3360 & 7700 & 7 & $2 \cdot 3$ \\
\hline 8 & $\mathbf{M}$ & $5 \cdot 3$ & 42 & 18 & 3920 & 7700 & 6 & $3 \cdot 5$ \\
\hline 9 & $\mathbf{M}$ & 10 & 72 & 18 & 6720 & 16800 & 24 & (a) 3.5 (b) 4.8 \\
\hline 10 & $\mathbf{M}$ & $7 \cdot 3$ & 66 & 33 & 9240 & 18400 & 9 & $3 \cdot 8$ \\
\hline 11 & $\mathbf{M}$ & 14 & 36 & 9 & 5040 & 6300 & 5 & 8 \\
\hline 12 & $\mathbf{M}$ & $12 \cdot 5$ & 48 & 12 & 1950 & 4900 & 3 & 1 \\
\hline 13 & $\mathbf{M}$ & $14 \cdot 8$ & $90 \ddagger$ & 22 & 7500 & 8900 & 27 & 5 \\
\hline 14 & $\mathbf{M}$ & 6 & $78 \S$ & 26 & 7000 & 14000 & 34 & (a) 1 (b) 1.5 (c) 1.7 (d) 2.1 (e) 3 \\
\hline 15 & $\mathbf{M}$ & 11 & $-\dagger$ & $-\dagger$ & 1505 & 5810 & 13 & 8 \\
\hline 16 & $\mathbf{F}$ & 11.8 & 60 & 13 & 3500 & 10000 & 24 & $4 \cdot 8$ \\
\hline 17 & $\mathbf{F}$ & $11 \cdot 3$ & 60 & 12 & 6720 & 12000 & 20 & 6 \\
\hline
\end{tabular}

*Received cyclophosphamide $4725 \mathrm{mg}$; †received chlorambucil $520 \mathrm{mg}$ and vinblastine $61 \mathrm{mg}$; †received cytosine arabinoside $300 \mathrm{mg} ; \S$ received adriamycin $270 \mathrm{mg}$, CCNU $500 \mathrm{mg}$, and vinblastine $50 \mathrm{mg}$.

60 minutes after an intravenous injection of luteinising hormone-releasing hormone (LH-RH) in a dose of $100 \mu \mathrm{g} / \mathrm{m}^{2}$ up to a maximum of $100 \mu \mathrm{g}$. In 10 of the 15 males Leydig cell function was assessed by a human chorionic gonadotrophin (hCG) stimulation test. ${ }^{5}$ Plasma testosterone was measured by celite column chromatography and subsequent radioimmunoassay. ${ }^{6}$ Serum levels of TSH, triiodothyronine, thyroxine, FSH, and $\mathrm{LH}$ were measured by specific radioimmunoassays. ${ }^{7}$

Case 14 was investigated on several different occasions as the initial results indicated progressive testicular dysfunction.

Six patients provided semen for analysis on two different occasions.

An LH-RH test was also performed in a control group of 41 normal boys and 14 young adult men (age range 23-36 years). Fifteen of the boys were prepubertal, 16 early pubertal (stages $\mathbf{P} 2$ or $\mathrm{P} 3$ ), and 10 late pubertal (stages P4 or P5). Because there were few control subjects, stages P2 and P3, and stages P4 and P5 were combined. The lack of significant difference in the gonadotrophin responses to LH-RH between stages P2 and P3 and between stages P4 and P5, as shown in the study by Dickerman et al. ${ }^{8}$ validated this procedure.

The normal control data for the hCG tests were provided by 9 prepubertal boys originally investigated for possible hormonal disorders and who later proved to be endocrinologically normal.

\section{Results}

Eight males had been prepubertal when they received their chemotherapy and in 5 of them puberty has proceeded normally or even been completed. The other 3 remain prepubertal at ages of $9.8,10$, and 11.8 years. Seven boys were pubertal at the time of treatment, 4 of whom have completed pubertal maturation. Four of the 5 men (Cases 1, 6,11 , and 15) had small testes-less than $15 \mathrm{ml}$-and all 5 late pubertal males (Cases 3, 4, 5, 7, and 9) had small testes (mean $7 \mathrm{ml}$ ) in comparison with the degree of pubertal development. Only one (Case 3) developed gynaecomastia and this was slight.

The 2 females had been treated between ages 11 and 12 years. Menarche had already occurred in Case 16 at age 11 years. Her periods were regular even while receiving chemotherapy. Case 17 was aged 14 years when menarche subsequently occurred. Her menstrual cycle is regular and ovulatory, as indicated by a plasma progesterone level of $>25$ $\mathrm{nmol} / 1(7.87 \mathrm{ng} / \mathrm{ml})$ on the $21 \mathrm{st}$ day of the cycle.

Basal serum FSH and LH concentrations and the peak gonadotrophin responses to LH-RH in the 15 males are shown in Figs 1 and 2. Cases 4, 5, 9, and 14 were studied more than once. The results for the 5 men have been graphically compared with those of the late pubertal controls. The comparison is valid as there is no significant difference between the basal serum FSH levels and the peak FSH and LH responses to LH-RH in the late pubertal and young adult control groups. The basal serum LH level is significantly higher in the young adult group however, and the upper limit of our normal range for this age group is $11.0 \mathrm{mU} / \mathrm{ml}$ rather than $8.0 \mathrm{mU} / \mathrm{ml}$ as in the late pubertal group.

All 4 prepubertal subjects had normal basal and peak gonadotrophin responses to LH-RH. Four subjects were studied in early puberty. Case 12 
showed no evidence of any abnormality of gonadotrophin secretion, Cases 4 (a) and 9 (a) had increased basal and stimulated FSH levels but normal LH levels. The results of Case 14 were particularly interesting as they showed an evolving pattern of abnormally raised gonadotrophin levels despite the increasing length of time since chemotherapy had been completed. Seven of the 10 late pubertal or adult subjects showed a raised basal serum FSH level and an exaggerated peak FSH response to LH-RH. Case 1 had a raised basal serum FSH level but a peak FSH response to LH-RH that was just within normal limits. Six of the 8 with raised FSH levels showed abnormalities of either the basal or stimulated LH level.

The basal testosterone levels and testosterone responses to hCG are shown in Table 2. The posthCG testosterone levels in the prepubertal control group ranged from 5.4 to $20.2 \mathrm{nmol} / 1$ (1.56 to $5.83 \mathrm{ng} / \mathrm{ml}$ ) with a mean 10 -fold rise above the basal level. Three of the 4 prepubertal patients showed subnormal testosterone responses to hCG. Case 14 showed a subnormal testosterone response to hCG on the first two occasions $(a, b)$ followed by a normal response on the third occasion (d), and

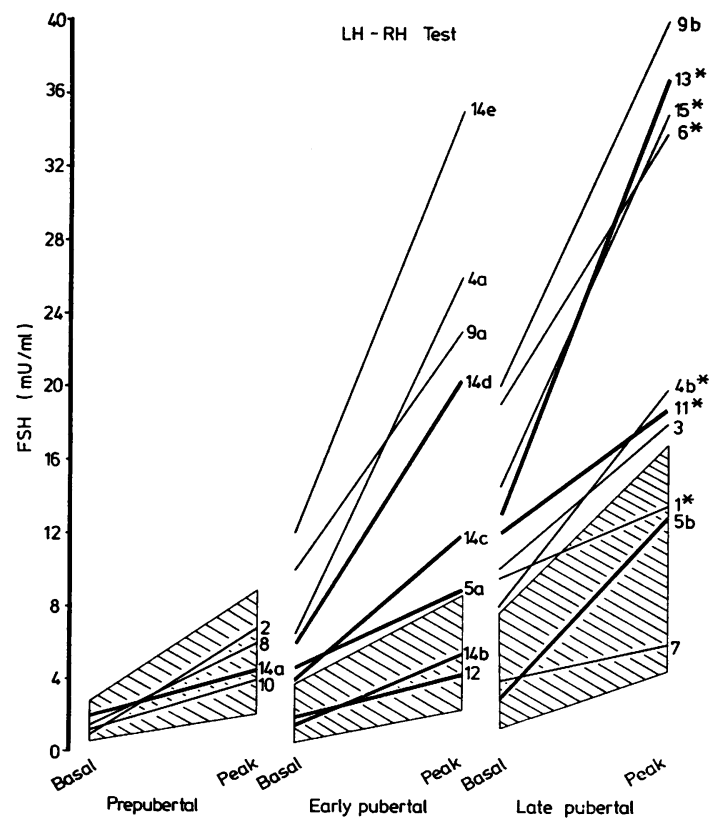

Fig. 1 Basal and peak FSH concentrations after LH-RH compared with normal boys of similar pubertal maturation. Normal range of values for each pubertal stage is shown (shaded area). Asterisks denote the azoospermic subjects.

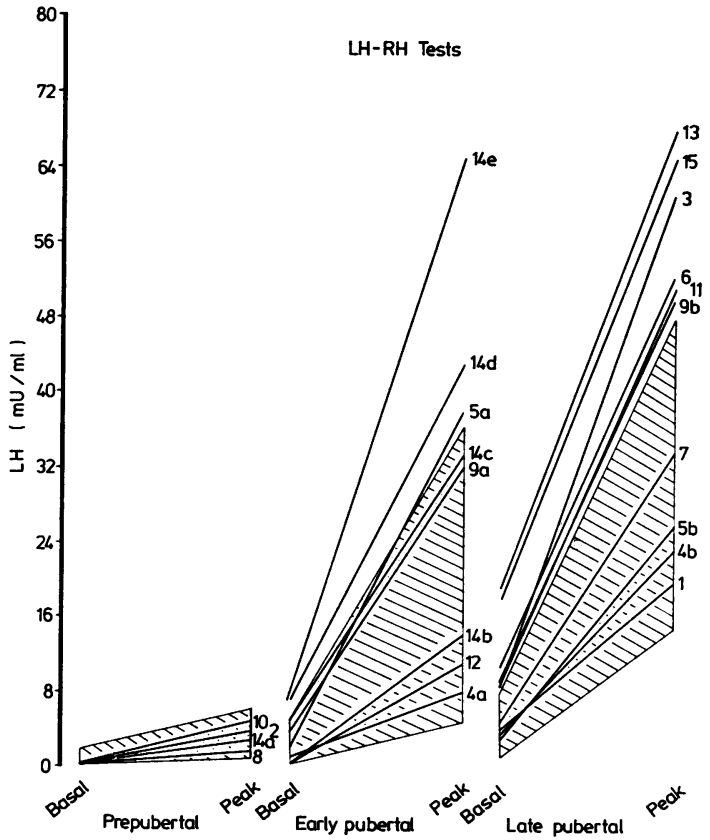

Fig. 2 Basal and peak $L H$ concentrations after LH-RH compared with normal boys of similar pubertal maturation. Normal range of values for each pubertal stage is shown (shaded area).

eventually an appropriate rise in his basal testosterone level (e). The normal range for the basal testosterone level in young adult men is between 10 and $35 \mathrm{nmol} / 1(2 \cdot 88$ and $10 \cdot 1 \mathrm{ng} / \mathrm{ml})$. All our late pubertal and adult males have basal testosterone levels within the normal range. In addition all those tested show a significant testosterone response to hCG stimulation, although we cannot say if the stimulated testosterone levels are as high as in normal young adult men.

Each of the 6 males (Fig. 1) who provided semen for analysis was azoospermic. Four of the 6 had only received combination chemotherapy, the remaining two (Cases 11 and 13) had received both combination chemotherapy and small doses of testicular irradiation. Semen analysis was carried out between 2.4 and 8 (mean $5 \cdot 3$ ) years after treatment had ended.

Thyroid function tests were normal in 6 subjects. In 11 there was biochemical evidence of compensated thyroid dysfunction, in that they had normal serum triiodothyronine $(1 \cdot 2-3 \mathrm{nmol} / 1 ; 0 \cdot 78-1.95$ $\mathrm{ng} / \mathrm{ml})$ and thyroxine $(50-150 \mathrm{nmol} / 1 ; 3.9-11.7$ $\mu \mathrm{g} / 100 \mathrm{ml}$ ) levels with a slightly increased serum TSH level (range 7-22 mU/1; normal $₹ 6 \mathrm{mU} / \mathrm{l}$ ). All 11 had received neck irradiation. 
Table 2 Pubertal status, basal testosterone level, and testosterone response to hCG stimulation

\begin{tabular}{|c|c|c|c|}
\hline Case & Stage of puberty & $\begin{array}{l}\text { Basal } \\
\text { testosterone } \\
\text { (nmol/l) }\end{array}$ & $\begin{array}{l}\text { Testosterone level } \\
(\text { (nmol/l) after hCG }\end{array}$ \\
\hline 2 & Prepubertal & $<1 \cdot 0$ & $3 \cdot 8$ \\
\hline 8 & Prepubertal & $<0.3$ & $2 \cdot 7$ \\
\hline 10 & Prepubertal & $<0.8$ & $10 \cdot 0$ \\
\hline $14 a$ & Prepubertal & $1 \cdot 3$ & $2 \cdot 4$ \\
\hline $14 b$ & Early pubertal & $<0.6$ & 3.0 \\
\hline $14 d$ & Early pubertal & $1 \cdot 3$ & 10.0 \\
\hline $14 \mathrm{e}$ & Early pubertal & $5 \cdot 0$ & - \\
\hline 5 & Early pubertal & $4 \cdot 0$ & - \\
\hline 12 & Early pubertal & $<1.5$ & $6 \cdot 5$ \\
\hline $4(a)$ & Early pubertal & $<0.6$ & $11 \cdot 2$ \\
\hline 4(b) & Late pubertal & 10 & 41 \\
\hline 9 & Late pubertal & 13 & 35 \\
\hline 7 & Late pubertal & $10 \cdot 5$ & $26 \cdot 5$ \\
\hline 3 & Late pubertal & $13 \cdot 5$ & 19 \\
\hline 1 & Adult & 32 & 58 \\
\hline 6 & Adult & 17 & - \\
\hline 11 & Adult & $21 \cdot 7$ & - \\
\hline 13 & Adult & 13 & - \\
\hline 15 & Adult & $18 \cdot 5$ & - \\
\hline
\end{tabular}

Conversion: SI to traditional units-testosterone: $1 \mathrm{nmol} / 1 \approx 0.288$ $\mathrm{ng} / \mathrm{ml}$.

\section{Discussion}

Gonadal function in adult men is more vulnerable to damage by combination chemotherapy than it is in women. ${ }^{1220}$ The age of the woman is an important factor in determining if ovarian failure is likely to follow such treatment. The fact that the number of oocytes decreases steadily with increasing age suggests that ovarian function in the prepubertal and pubertal girl may be less susceptible to cytotoxic-induced damage. However it is clear that the prepubertal ovary is not immune from such damage. ${ }^{9}$ Ovarian function appeared intact in our two females despite previous treatment with MOPP, but had more females been studied we might have noted a greater incidence of cytotoxic-induced ovarian failure.

There have been reports of recovery of spermatogenesis in men previously treated with single cytotoxic agents $^{10}$ or a combination of 2 or 3 drugs $^{11}$ but the outlook for men previously treated with MVPP or MOPP appears poor. In our study ${ }^{20} 42$ out of 49 men were azoospermic after 6 courses of MVPP, and 5 of the remaining 7 had a sperm count below 1 million $/ \mathrm{ml}$. Furthermore 10 of 11 patients studied between 6 and 8 years after the end of chemotherapy were azoospermic. Sherins et al. ${ }^{3}$ also found severe tubular damage in pubertal boys treated for Hodgkin's disease with MOPP. Eight out of 9 had a raised basal serum FSH level, and in all 6 biopsied, testicular histology showed germinal aplasia. Sherins et al. $^{3}$ estimated the serum FSH level in serial samples from 4 of their 9 pubertal boys. In 2 of them the serum FSH level progressively decreased to normal, but in the other two gonado- trophin concentrations remained high. This suggested that permanent sterility might not be an inevitable consequence of MOPP therapy in the pubertal male. Our results also indicate severe tubular damage after MOPP therapy. Eight of 10 late pubertal or adult subjects show a raised basal serum FSH level, 9 have small testes, and 6 are azoospermic. Only one (Case 5), out of the 4 subjects studied on more than one occasion, had a raised FSH level initially and a normal FSH level on subsequent testing. Despite the normal FSH level he was noted to have small testes. The 6 azoospermic subjects were studied between 2.4 and 8 (mean 5.3) years after chemotherapy had ended which suggests that recovery of spermatogenesis is unlikely. It should be pointed out that there were certain differences in the treatment received by our children compared with those of Sherins et $a .^{3}$ Three of our 10 late pubertal or adult males had received an appreciable radiation dose to the testes as well as combination chemotharapy. Moreover it would appear that our male patients received more procarbazine and vincristine than those studied by Sherins et al. ${ }^{3}$

It has become increasingly difficult to estimate the contribution of any one single drug to the testicular damage caused by combination chemotherapy such as MOPP or MVPP. Testicular damage in the human has been attributed to mustine ${ }^{12}$ (or chlorambucil), ${ }^{13}$ vinblastine, ${ }^{14}$ and prednisolone. ${ }^{15}$ Vincristine ${ }^{16}$ decreases amino-acid incorporation into spermatogenic cells of the rat and procarbazine has been shown to induce complete germinal aplasia in the rat $^{17}$ and the primate. ${ }^{18}$ It is likely that in our patients treated with MOPP the drugs mainly responsible for the severe tubular damage were mustine and procarbazine.

The 4 prepubertal boys in our study showed normal basal gonadotrophin levels and gonadotrophin responses to LH-RH. We have concluded in earlier studies on prepubertal boys with radiationinduced ${ }^{19}$ or cytotoxic-induced ${ }^{5}$ testicular damage that tests of testicular function are unlikely to detect such damage. The FSH levels of Case 14 were normal in prepubertal life and abnormal in early puberty. During 2 years he showed an evolving pattern of abnormally high gonadotrophin levels despite the increasing length of time since the end of chemotherapy. Several other subjects who were treated before the onset of puberty showed evidence of severe tubular damage during puberty or adulthood. For these reasons we believe it likely that most, if not all, our prepubertal boys have sustained testicular damage from the MOPP therapy.

Some degree of breast development may be seen in at least half of normal boys at some time during 
puberty. In our study gynaecomastia affected only one, compared with 9 out of 13 pubertal boys with gynaecomastia reported by Sherins et al. ${ }^{3}$ Such a high incidence of moderate or severe gynaecomastia was a major clinical feature of that study. It is difficult to understand this disparity. It is possible that some of our older boys had already experienced a minor degree of breast development and that this had regressed before chemotherapy started. However none had had moderate or severe gynaecomastia. Eight of our 12 pubertal boys had received mantle field irradiation but the radiation dose reaching the breast bud is minimal with this radiation field as the breasts are covered by lead blocks designed to protect as much lung tissue as possible from radiation damage. Indeed the one individual (Case 3) who developed gynaecomastia had received mantle field irradiation. Gynaecomastia in 1 out of 12 pubertal boys is similar to the incidence we observed in adult men (7 out of 74 ) treated with MVPP for Hodgkin's disease. ${ }^{20}$

Three of the 4 prepubertal subjects showed subnormal testosterone responses to hCG stimulation although in one (Case 14) the impaired testosterone response was transient. In addition a raised basal LH level or exaggerated peak LH response to LH-RH was found in 8 pubertal or adult subjects. The abnormalities in $\mathrm{LH}$ and testosterone concentrations suggest that Leydig cell damage has occurred. However, our 9 late pubertal or adult males (Table 2) have basal testosterone levels within the normal range and all show a significant testosterone response to hCG stimulation. Pubertal development has progressed normally in these nine. Two men are now married and have normal libido and sexual activity. Thus although evidence of a minor degree of Leydig cell dysfunction is common, frank Leydig cell failure is rare.

We conclude that severe testicular damage is common after MOPP therapy in childhood. The germinal epithelium is particularly vulnerable and the resultant azoospermia is likely to be irreversible. The Leydig cells are less susceptible to cytotoxicinduced damage. Pubertal development proceeds quite normally and there is no indication for androgen replacement therapy.

We thank Miss $\mathbf{M} \mathbf{J}$ Moores for typing the manuscript. This work was supported by a grant from the Leukaemia Research Fund.

\section{References}

1 Chapman R M, Sutcliffe S B, Rees L H, Edwards C R W, Malpas J S. Cyclical combination chemotherapy and gonadal function. Lancet 1979; i: 285-9.

2 Chapman R M, Sutcliffe S B, Malpas J S. Cytotoxic- induced ovarian failure in women with Hodgkin's disease. JAMA 1979; 242: 1877-81.

3 Sherins R J, Olweny C L M, Ziegler J L. Gynaecomastia and gonadal dysfunction in adolescent boys treated with combination chemotherapy for Hodgkin's disease. N Engl J Med 1978; 299: 12-6.

4 Tanner J M. Growth at adolescence, second edition. Oxford: Blackwell, 1962.

5 Shalet S M, Hann I M, Lendon M, Morris Jones P H, Beardwell C G. Testicular function after combination chemotherapy in childhood for acute lymphoblastic leukaemia. Arch Dis Child 1981 ; 56: 275-8.

6 Anderson D C, Hopper B R, Lasley B L, Yen S S C. A simple method for the assay of eight steroids in small volumes of plasma. Steroids 1976; 28 : 179-96.

7 Shalet S M, Beardwell C G, Morris Jones P H, Pearson D. Pituitary function after treatment of intracranial tumours in children. Lancet 1975; ii: 104-7.

8 Dickerman Z, Prager-Lewin R, Laron Z. Response of plasma LH and FSH to synthetic LH-RH in children at various pubertal stages. Am J Dis Child 1976; 130: 634-8.

9 Shalet S M. Effects of cancer chemotherapy on gonadal function of patients. Cancer Treat Rev 1980; 7: 141-52.

10 Buchanan J D, Fairley K F, Barrie J U. Return of spermatogenesis after stopping cyclophosphamide therapy. Lancet 1975; ii: 156-7.

11 Roeser H P, Stocks A E, Smith A J. Testicular damage due to cytotoxic drugs and recovery after cessation of therapy. Aust NZJ Med 1978: 8: 250-4.

12 Spitz S. The histological effects of nitrogen mustards on human tumors and tissues. Cancer 1948; 1 : 383-98.

13 Richter P, Calamera J C, Morgenfeld M C, Kierszenbaum A L, Lavieri J C, Mancini R E. Effect of chlorambucil on spermatogenesis in the human with malignant lymphoma. Cancer 1970; 25: 1026-30.

14 Vilar O. Effect of cytostatic drugs on human testicular function. In: Mancini R E, Martini L V, eds. Male fertility and sterility. New York: Academic Press, 1974: 423-40.

15 Mancini R E, Lavieri J C, Muller F, Andrada J A, Saraceni D J. Effect of prednisolone upon normal and pathologic human spermatogenesis. Fertil Steril 1966; 17: 500-13.

16 Lee I P, Dixon R L. Antineoplastic drug effects on spermatogenesis studied by velocity sedimentation cell separation. Toxicol Appl Pharmacol 1972; 23: $20-41$.

17 Lee I P, Dixon R L. Effects of procarbazine on spermatogenesis determined by velocity sedimentation cell separation technique and serial mating. J Pharmacol Exp Ther 1972; 181: 219-26.

18 Sieber S M, Correa P, Dalgard D W, Adamson R H. Carcinogenic and other adverse effects of procarbazine in non-human primates. Cancer Res 1978; 38: 2125-34.

19 Shalet S M, Beardwell C G, Jacobs H S, Pearson D. Testicular function following irradiation of the human prepubertal testis. Clin Endocrinol (Oxf) 1978; 9: 483-90.

20 Whitehead E, Shalet S M, Blackledge G, Todd I, Crowther D C, Beardwell C G. The effects of Hodgkin's disease and combination chemotherapy on gonadal function in the adult male. Cancer 1982; 49: 418-22.

Correspondence to Dr S M Shalet, Christie Hospital and Holt Radium Institute, Wilmslow Road, Withington, Manchester M20 9BX.

Received 3 August 1981 